\title{
Neurosurgery for mental disorders: a review
}

\author{
A Heeramun-Aubeeluck $\mathbf{1}, \mathbf{Z} \mathbf{L u}^{\mathbf{2}}$ \\ 1Tongji Hospital, affiliated to Tongji University, Shanghai, China \\ 2Shanghai Mental Health Center, affiliated to Jiao Tong University, Shanghai, China
}

\begin{abstract}
Neurosurgical interventions date back to ancient civilization, 5100 BC through a practice known as trephination. Due to past abuse and ethical considerations, neurosurgical interventions in psychiatry remain a controversial issue. This article aims to review the different surgical techniques and their current application in the treatment of psychiatric disorders. The U.S Food and Drug Administration (FDA) gave its approval for vagal nerve stimulation (VNS) for the management of treatment-resistant depression in 2005 and deep brain stimulation (DBS) for refractory obsessive-compulsive disorders (OCD) in 2009. These invasive but non destructive techniques represent the future of neurosurgery for mental disorder
\end{abstract}

Keywords: Psychosurgery; Functional neurosurgery; Neurosurgery for mental disorder

Received: $22-02-2012$

Accepted: 24-06-2012

doi: http://dx.doi.org/10.4314/ajpsy.v16i3.23

\section{Introduction}

The term "psychosurgery" was coined by Egas Moniz in 1937. ${ }^{1}$ However, the first reported surgical intervention for psychiatric diseases was by Burkhardt in 1891. The latter described the use of bilateral cortical excision for the treatment of demented and aggressive patients. ${ }^{2}$ Moniz performed prefrontal leucotomies on patients with chronic mental illness through the injection of absolute alcohol following Fulton and Jacobson's report of frontal lobotomy in primates. ${ }^{1,3}$ In spite of the lack of documented data regarding success of this method and partly due to lack of effective treatment options at that time, Moniz was awarded the Nobel Prize in Medicine and Physiology in 1949. Prefrontal lobotomy was introduced in the United States in 1942 by Freeman and Watts, following which there was an upsurge in surgical interventions during the years 1943 to $1954 .{ }^{4}$ More precise techniques were developed by the late 1940's and included procedures such as orbital undergryrus cutting, bilateral inferior leucotomy, bimedial leucotomy and transorbital leucotomy. Major breakthroughs and development however, came in the early 1960's. In 1962, Foltz and White described stereotactic anterior cingulotomy and later in 1964, Knight

Correspondence

Dr L Zheng

Tongji Hospital, Department of Psychosomatic Medicine

No. 389 Xincun Road, Shanghai 200065, China

email: luzheng@tongji.edu.cn described subcaudate tractotomy. ${ }^{5,6}$ Anterior cingulotomy was proposed by Lars Leksell in 1972. ${ }^{7}$ One year later Kelley reported findings from combined techniques form subcaudate tractotomy and cingulotomy and this procedure was termed limbic leucotomy. ${ }^{8}$ Other investigators reported case reports of other techniques such as thalamothomy and amygdalotomy but with the introduction of chlorpromazine and newer psychotropic medications psychosurgery lost its popularity as a treatment modality. Nowadays, due to ethical, moral and legal implications, psychosurgery can only be found in selected centres across the globe.

\section{From Psychosurgery to Neurosurgery for Mental Disorder (NMD)}

The World Health Organization in 1976 defined psychosurgery, also known as functional neurosurgery or limbic system surgery, as: "The selective surgical removal or destruction of nerve pathways for the purposes of influencing behaviour". 9

In modern times, this statement no longer encompasses the novel techniques that have emerged. A more updated definition was put forward by Berrios based on 4 criteria: (1) the direct interference with brain tissue; (2) utilizing an irreversible procedure; (3) targeting normal brain tissue; (4) with the goal of alleviating mental illness. ${ }^{10}$ Due to stigma attached to the term "psychosurgery", many practitioners prefer the use of the term "Neurosurgery for Mental Disorder or NMD". Furthermore as Freeman states, the term neurosurgery for mental disorders emphasizes the use of 
surgical techniques in the management of specific disorders such as treatment-resistant depression and obsessivecompulsive disorders and not as a treatment for aggressive or anti-social behaviour disturbances. ${ }^{11}$ The Royal College of Psychiatrists defines neurosurgery for mental disorder as: "A surgical procedure for the destruction of brain tissue for the purposes of alleviating specific mental disorders carried out by a stereotactic or other method capable of making an accurate placement of the lesion". ${ }^{12}$

\section{Who benefits from neurosurgery for mental disorder?}

Unlike the freehanded practice during the 1940's to early 1950's, neurosurgical interventions for alleviating mental disorder is allowed only in specific circumstances and performed only in few specialized centres across the globe.

Patients meeting the criteria for neurosurgical interventions are severely afflicted with chronic treatment resistant mental illnesses. However, in some cases, chronicity (prolonged period of disease without any period of symptomatic relief) becomes secondary to severity. All these patients must have shown treatment failure or been refractory to pharmacological and psychotherapeutic treatments. Whenever indicated other treatment modalities such as behavioural and electro-convulsive therapies must also have been tried and proved unsuccessful. Severity and disability are assessed by validated clinical research instruments. The patient should preferably be an adult (abovel8 years of age) and both patient and family consent are required prior to surgery. Family commitment to postoperative treatment program is essential for a better outcome.

Nowadays neurosurgery is reserved only for specific conditions namely severe obsessive-compulsive disorder and other obsessive-compulsive related disorders (e.g., Yale Brown Obsessive Compulsive Scale score of $>20$ ), severe anxiety disorders and severe treatment-resistant depression (e.g., Beck Depression Inventory score of $>30$ ). When the cause of affective or obsessional symptoms is as a result of pervasive developmental disorders, substance abuse, organic brain lesions or degenerative brain disorders, neurosurgical interventions are contraindicated. Disorders such as schizophrenia, personality disorders and anorexia nervosa have not proved to benefit from neurosurgery for mental disorder and hence they are not recommended for neurosurgical interventions.

\section{Techniques in neurosurgery for mental disorder}

With a focus on commonly practiced procedures in different countries, the surgical procedures are summarized below.

\section{Anterior capsulotomy}

Anterior capsulotomy also known as ACAPS is a procedure generating lesion within fibres connecting the ventromedial and orbitofrontal cortex and anterior cingulate gyrus with the thalamus, amygdala and hippocampus. ${ }^{13}$ The lesion may be produced by thermal coagulation or focal gamma radiation and anatomically is located in the anterior one third of the internal capsule $5 \mathrm{~mm}$ behind the tip of the frontal horns and $20 \mathrm{~mm}$ lateral to the midline. ${ }^{14}$ It can be done under general anaesthesia or local anaesthesia with sedation.

\section{Anterior cingulotomy}

Anterior cingulotomy or ACING is a procedure that can be performed under general anaesthesia or local anaesthesia with sedation. By means of MRI guided stereotactic thermocoagulation, a lesion of 8-10 $\mathrm{mm}$ in lateral diameter is produced in the anterior cingulate gyrus and cingulate bundle. This lesion is placed $20-25 \mathrm{~mm}$ posterior to anterior tip of the lateral ventricles and $7 \mathrm{~mm}$ from midline and extends $2 \mathrm{~mm}$ dorsally from the corpus callosum. ${ }^{15}$

\section{Stereotactic subcaudate tractotomy}

Stereotactic subcaudate tractotomy consists of division of fibres connecting the orbital cortex to subcortical and limbic areas. This procedure is done under general anaesthesia and though stereotactic guidance. Lesion is placed $5 \mathrm{~mm}$ anterior to the sella, $15 \mathrm{~mm}$ from the midline, and 10-1 $1 \mathrm{~mm}$ above the planum in the subcaudate white matter by radioactive yttrium-90 rods or by thermocoagulation. ${ }^{16}$

\section{Limbic leucotomy}

Limbic leucotomy is not commonly used in the UK as compared to the US. Lesion targets fibres from the anterior cingulate cortex, the cingulum bundle and frontostriatolimbic circuits. The techniques employed are a combination of anterior cingulotomy and stereotactic subcaudate tractotomy. ${ }^{13}$

\section{Vagus nerve stimulation}

Vagus nerve stimulation (VNS) consists of subclavicular implantation of a pulse generator device similar to a cardiac pacemaker. This procedure can only be carried out on the left vagus nerve as the right vagus nerve is crucial for cardiac function. The device consists of a bipolar electrode which is wrapped around the left vagus nerve in its course through the neck. The fibres from the vagus nerve connect with cells in the nucleus tractus solitarius (NTS) which has projections to the forebrain, hypothalamus, amygdala, median raphe nucleus and locus coerulus. The stimulator is typically activated for 30 seconds every 5 minutes but can be altered by means of a telemetric wand connected to a palmtop computer. ${ }^{17}$

\section{Deep brain stimulation}

Deep brain stimulation (DBS) is usually carried out under local anaesthesia. Under CT or MRI image guidance, electrodes are implanted bilaterally in the anterior limbs of the internal capsule or in the white matter projections from the anterior cingulated. ${ }^{18}$ This is followed by subcutaneous abdominal or subclavicular implantation of programmable generators which connect to the electrodes by subcutaneous wires. ${ }^{17,19}$ Low frequency stimulation and high frequency stimulation offer the possibility to activate or inhibit neuronal networks. ${ }^{20}$

\section{Adverse effects}

Surgical techniques generating lesions to brain tissue are associated with two main types of adverse effects namely general surgical and procedure specific. The former comprises of general risks such as high risk anaesthesia vascular injury (<1\%), transient confusional states $(<21$ 
days), infections (median duration until presentation: 1.5 months), post-surgical epilepsy (<10\% over 10 years) and surgical mortality rate $(<1 \%),{ }^{17,21}$

Significant weight gain has been reported in females following anterior capsulotomy (21\%), stereotactic tractotomy (6.2\%) and bimedial leucotomy (12.5\%) but not with cingulotomy. ${ }^{14,17}$ Little evidence can be traced about personality changes following leucotomy. ${ }^{17}$ Surprisingly, following stereotactic neurosurgery, general intelligence is preserved or improved in attentional subcomponent Common adverse effects following VNS include voice alteration (53-54\%), headache (23\%), neck pain (13-17\%), dyspnoea (16-17\%) and cough (5-13\%).17,22 These adverse effects are transient except for voice alteration which might persist in $21 \%$ of patients. Besides skin erosions and infections, the development of punding can be quite distressing post DBS. Punding is characterised by repetitive purposeless activi $\neg$ ties that are typically very disruptive to all but the patient. ${ }^{23}$ Other behavioural changes such as depression, anxiety, hypomania, hypersexuality, apathy, personality changes, and aggression might occur following DBS. ${ }^{24,25}$ Suicide has also been reported following DBS and since it is independent of symptom improvement, careful follow-up is mandatory. ${ }^{26}$ It should be pointed out that hardware failures or migrations of wire are possible complications resulting from VNS and/or DBS.

\section{Clinical applications}

\section{Obsessive-compulsive disorders (OCD)}

Obsessive-compulsive disorder (OCD) is characterized recurrent intrusive ideas or images in a stereotyped form (obsessional thoughts) and/or ritualistic stereotyped behaviours (compulsive acts). It affects $2 \%$ of the general population and $25-40 \%$ of patients are refractory to treatment. ${ }^{27,28}$ The exact circuitry involved in OCD is unknown. It is hypothesized that the neural circuitry involved in OCD is related to the following 3 components:

(1) cortico-thalamic pathway: positive feedback loop from the orbital and prefrontal cortex through the anterior limb of the internal capsule;

(2) cortex-striatum-thalamus-cortex loop (CSTC): inhibitory pathway connecting the orbitofrontal cortex, caudate nucleus, globus pallidus and thalamus;

(3) portions of the limbic system including the hippocampus, mamillary bodies and fornix linking to the thalamus and to the anterior cingulate cortex. ${ }^{29}$

It is speculated that excessive stimulation of the orbitofronto-thalamic circuit or decreased inhibition of the CSTC loop might lead to OCD symptoms. Thus, the targets for surgical interventions in OCD include the anterior limb of internal capsule, the anterior cingulate gyrus and nucleus accumbens. ${ }^{30}$

Ablative surgical procedures such as anterior capsulotomy and anterior cingulotomy have proved to be beneficial in $45-65 \%$ of patients with intractable OCD. ${ }^{31}$ Studies on long term follow-up of patients with OCD have also shown evidence of not only clinical improvement but also of cognitive improvement. ${ }^{32-35}$

Interestingly with the emergence of reversible and nondestructive methods such as DBS, the treatment of severe disabling or intractable obsessive-compulsive disorders has been elevated to new heights. The US Food and Drug Administration (FDA) gave its approval for use of DBS in treatment-resistant OCD as from February, 2009. The most common surgical target for DBS is the anterior capsule and it has been proposed that termination of activity at this site would abolish the pathological circuit which consists of loop fibres connecting the cortex to the thalamus. ${ }^{29} \mathrm{~A}$ fortuitous observation revealed improvement of comorbid obsessivecompulsive symptoms after deep brain stimulation of the subthalamic nucleus. ${ }^{36,37}$ This led to the conduction of another randomized trial in patients with obsessivecompulsive disorders and it was found that deep brain stimulation of the subthalamic nucleus significantly decreased the severity of obsessive-compulsive disorder. ${ }^{38}$

\section{Affective disorder}

Major depressive disorder (MDD) is a multidimensional syndrome manifesting as depressed mood and loss of interest or pleasure coupled with increased fatigability, excessive guilt or feelings of worthlessness and significant changes in weight, sleep patterns, psychomotor function. MDD affects about 10\% of the world population and remission rates on currently available treatments rarely exceed 30\%.39,40 The exact mechanism of depression is unknown. Based on hypothesized neural circuitry of depression, 3 components are thought to be crucial. They are: the cortical component, the subcortical component and the modulatory component. ${ }^{29}$ The cortical component includes the prefrontal cortex, dorsal part of the anterior cingulate gyrus and areas of the premotor cortex. It also has access to the striatum and subsequently forms a feedback loop with the striatum. As for the subcortical component, it also links with the striatum and then forms a feedback loop with the thalamus. It is comprised of the subgenual anterior cingulate, the orbitofrontal cortex, the limbic structures including nucleus accumbens and amygdala.The modulatory component comprising of the amygdala, pregenuate anterior cingulate gyrus and hypothalamic-pituitary-adrenal (HPA) axis links the cortical component to the subcortical component via inhibitory circuits. ${ }^{41}$ Surgical procedures aim at creating lesions in the anterior cingulate cortex (cingulotomy), projections from the orbitofrontal cortex and/or cingulate cortex to the basal ganglia and medial thalamus (capsulotomy and subcaudate tractotomy) or a combination of both (limbic leucotomy). A recent 7 year follow-up study on efficacy of limbic leucotomy in major affective disorders showed significant reduction in depressive symptoms, anxiety-like symptoms as well as negative symptoms. ${ }^{42}$

Over the past decade, newer techniques which are less crude and destructive have emerged. In July 2005, FDA gave its approval for VNS for treatment-resistant depression. The response rates to VNS were as follows: $78 \%$ in patients with 2-3 failed antidepressants therapy, 63\% in patients with 4-5 failed antidepressants therapy and $25 \%$ in those with 67 failed antidepressants therapy. ${ }^{43}$ Thus, VNS seems to be more effective in patients with low-moderate antidepressant drug resistance and who showed some positive response to electro-convulsive therapy (ECT). ${ }^{44}$ The use of DBS in depressive disorders is still on an experimental basis. 
Several sites have been targeted such as orbito-frontal cortex, anterior cingulate gyrus, corpus striatum, globus pallidus, ventral capsule/ventral striatum

ventralcapsule/ventral commisure, nucleus accumbens, and inferior thalamic peduncle. ${ }^{45}$ Recently, a new model of depression was proposed and it was postulated that deep brain stimulation of the white matter in the subgenual cingulate cortex adjacent to Broadmann area 25 would be beneficial to treatment refractory depression. ${ }^{46,18}$ After clinical trial, $60 \%$ of patients showed improvement and 35\% met remission criteria. 18

Bipolar disorder is a complex disorder characterized by the presence of mania and depression (Bipolar I disorder) and hypomania and depression (Bipolar II disorder). The lifetime prevalence of these conditions is estimated at around 2-4\%, ${ }_{4}^{47,48}$ The first technique that was used in bipolar disorders was leucotomy, with the aim of creating lesions in the white matter of the frontal lobes. Ablative surgical procedures in bipolar disorder have generated mixed results. It should be noted that most studies had been conducted during the 1950's and 1960's. In a more recent study with a 7 year follow-up, it was found that limbic leucotomy did not significantly improve mania symptoms in bipolar disorder as compared to depressive symptoms and anxiety-like symptoms symptoms. ${ }^{42}$

A post-hoc analysis from a large mixed-population trial on VNS in bipolar disorders suggest possible efficacy as a treatment modality in refractory cases. ${ }^{49}$ However, more randomized trials with large sample size are required to establish the efficacy of VNS in bipolar disorders. Literature search revealed no reported trials on application of DBS in the treatment of bipolar disorders.

\section{Conclusion}

Novel neurosurgical interventions characterized by nondestructive and chronic stimulation of brain tissue are promising techniques for management of treatmentresistant depression and OCD disorders. At present VNS is an approved technique for the management of refractory depression. Application of DBS in treatment-resistant OCD has been approved while its usage in depression is still under trial. Nonetheless, it is essential to have a multidisciplinary approach with careful regulation and ethical administration when considering neurosurgical interventions in mental disorder as the latter are also linked to cognitive and clinical neurosciences.

\section{References}

1. Moniz E. Prefrontal leucotomy in the treatment of mental disorders. 1937. Am J Psychiatry 1994; 151 (6 Suppl): 1379-1385. [PMID: 8192205$]$.

2. Burckhardt G. Uber Rindenexcisionen, als Beitrag zur operativen Therapie der Pyschosen. Z Psychiatr 1891; 47: 463-548. (In German).

3. Fulton JF, Jacobson CF. Fonctions des lobes frontaux; etude comparee chez l'homme et les singes chimpanzes. In proceedings of the International Neurological Congress, London, $1935: 552$

4. Freeman W, Watts JW. Psychosurgery: Intelligence, emotion and social behavior following prefrontal lobotomy for mental disorders. Springfield: Thomas, 1942.
5. Foltz EL, White LE Jr. Pain relief by frontal cingulotomy. Neurosurg 1962; 19: 89-94. [PMID: 13893868].

6. Knight GC. The orbital cortex as an objective in the surgical treatment of mental illness. The development of the stereotactic approach. Br J Surg 1954; 51: 114-124. [PMID: 14117767].

7. Lunsford LD. Lars Leksell. Notes at the side of a raconteur. Stereotact Funct Neurosurg 1996-1997; 67(3-4): 153-168. [PMID: $9311073]$

8. Kelley D, Richardson A, Mitchell-Heggs N. Stereotactic limbic leucotomy: neurophysiologic aspects and operative technique. Br J Psychiatry 1973; 123(573): 133-140. [PMID: 4582234].

9. Feldman RP, Goodrich JT. Psychosurgery: a historical overview. Neurosurgery 2001; 48(3): 647-659. [PMID:1 1270556].

10. Berrios GE. The origins of psychosurgery: Shaw, Burckhardt and Moniz. Hist Psychiatr 1997; 8(29): 61-81. [PMID: 11619209 ].

11. Freeman C. Neurosurgery for mental disorder in the UK. Psychiatric Bulletin 1997; 21: 67-69. [http://dx.doi.org/10.1192/pb.21.2.67].

12. Royal College of Psychiatrists. Neurosurgery for Mental Disorder. Report from the Neurosurgery Working Group of the Royal College of Psychiatrists. Psychiatric Bulletin 2002; 26: 276. [http://dx.doi.org/10.1192/pb.26.7.276-b].

13. Christmas D, Morrison C, Eljamel MS, Matthews K. Neurosurgery for mental disorder. APT 2004; 10: 189-199. [http://dx.doi.org/ 10.1192/apt.10.3.189].

14. Mindus P, Meyerson BA. Anterior capsulotomy for intractable anxiety disorders. In: Schmidek HH, Sweet WH, eds. Operative neurosurgical techniques: indications, methods, and results. Philadelphia: WB Saunders 1995:1443-1455.

15. Spangler WJ, Cosgrove GR, Ballantine HT Jr, Cassem EH, Rauch SL, Nierenberg A et al. Magnetic resonance image-guided stereotactic cingulotomy for intractable psychiatric disease. Neurosurgery 1996; 38:1071-1078. [PMID: 8727135].

16. Ovsiew F, Frim DM. Neurosurgery for psychiatric disorders. J Neurol Neurosurg Psychiatry 1997; 63: 701-705. [http://dx.doi.org/doi:10.1136/jnnp.63.6.701] [PMID: 9416800].

17. Christmas DMB, Curran S, Matthews K, Eljamel MS. Neurosurgery for mental disorder, vagus nerve stimulation and deep brain stimulation. Psychiatry 2009; 8(4): 139-143. [http://dx.doi.org/doi: 10.1016/j.mppsy.2009.01.007].

18. Mayberg HS, Lozano AM, Voon V, McNeely HE, Seminowicz D, Hamani $C$ et al. Deep brain stimulation for treatment-resistant depression. Neuron 2005; 45: 651-660. [http://dx. doi.org/doi: 10.1016/j.neuron.2005.02.014] [PMID: 15748841].

19. Farris $S$, Giroux M. Deep brain stimulation: A review of the procedure and the complications. JAAPA 201 1; 24(2):39-40, 4245. [PMID: 21387969$].$

20. Krack P, Hariz MI, Baunez C, Guridi J, Obeso JA. Deep brain stimulation: from neurology to psychiatry? Trends Neurosci 2010 33(10): 474-484. [http://dx.doi.org/doi:10.1016/j.tins.2010.07.002] [PMID: 20832128]

21. Dashti SR, Baharvahdat H, Spetzler RF, Sauvageau E, Chang SW, Stiefel MF et al. Operative intracranial infection following craniotomy. Neurosurg Focus 2008;24(6):E10. [PMID: 18518740].

22. Eljamel MS. Ablative neurosurgery for mental disorders: is there still a role in the 21 st century? A personal perspective. Neurosurg Focus 2008; 25 (1):E4. [PMID: 18590381].

23. Pallanti S, Bernardi S, Raglione LM, et al. Complex repetitive behavior: punding after bilateral subthalamic nucleus stimulation in Parkinson's disease. Parkinsonism Relat Disord 2010;16(6):376380. [http://dx.doi.org/doi: 10.1016/j.parkreldis.2010.02.011] 
[PMID: 20346726].

24. Greenberg BD, Malone DA, Friehs GM et al. Three-Year Outcomes in Deep Brain Stimulation for Highly Resistant ObsessiveCompulsive Disorder. Neuropsychopharmacology 2006; 31: 2384-2393. [http://dx.doi.org/doi: 10.1038/sj.npp. 13011 65] [PMID: 16855529].

25. Temel Y, Kessels A, Tan S, Topdag A, Boon P, Visser-Vandewalle V. Behavioural changes after bilateral subthalamic stimulation in advanced Parkinson disease: a systematic review. Parkinsonism Relat Disord 2006;12(5): 265-272.

[http://dx.doi.org/doi:10.1016/j.parkreldis.2006.01.004] [PMID $16621661]$

26. Soulas T, Gurruchaga JM, Palfi S, Cesaro P, Nguyen JP, Fénelon G. Attempted and completed suicides after subthalamic nucleus stimulation for Parkinson's disease. J Neurol Neurosurg Psychiatry 2008;79(8):952-954. [http://dx.doi.org/doi: 10.1136/jnnp.2007.130583] [PMID: 18403439].

27. Kessler RC, Berglund P, Delmer O, Jin R, Merikangas KR, Walters EE. Lifetime prevalence and age-of-onset distributions of DSM-IV disorders in the National Comorbidity Survey Replication. Arch. Gen. Psychiatry 2005; 62: 593-602.

[http://dx.doi.org/doi:10.1001/archpsyc.62.6.593] [PMID: 15939837].

28. Pallanti S, Quercioli L. Treatment-refractory obsessive-compulsive disorder: methodological issues, operational definitions and therapeutic lines. Prog Neuropsychopharmacol Biol Psychiatry 2006; 30 : 400-412. [http://dx.doi.org/doi: 10.1016/j.pnpbp.2005.11.028] [PMID: 16503369].

29. Shah DB, Pesiridou A, Baltuch GH, Malone DA, O'Reardon JP. Functional neurosurgery in the treatment of severe obsessive compulsive disorder and major depression. Psychiatry 2008; 5(9): 24-33. [PMID: 19727257].

30. Alexander GE, Crutcher MD, DeLong MR. Basal gangliathalamocortical circuits: parallel substrates for motor, oculomotor, "prefrontal" and "limbic" functions. Prog Brain Res 1990; 85: 119 146. [http://dx.doi.org/doi: 10.1016/S0079-6123(08)62678-3] [PMID 2094891].

31. Greenberg BD, Price LH, Rauch SL, Friehs G, Noren G, Malone D, et al. Neurosurgery for intractable obsessive compulsive disorder and depression: critical issues. Neurosurg Clin N Am 2003;14 199-212. [PMID: 12856488].

32. Mindus P, Rauch SL, Nyman H. Capsulotomy and cingulotomy as treatments for malignant obsessive-compulsive disorder: an update. In: Hollander, E., Zohar, J. (Eds.), Current Insights in ObsessiveCompulsive Disorder. Wiley and Sons Ltd; 1994: 245-276.

33. Nyman H, Andréewitch S, Lundbäck E, Mindus P. Executive and cognitive functions in patients with extreme obsessive-compulsive disorder treated by capsulotomy. Appl. Neuropsychol. 2001; 8(2): 91-98. [http://dx.doi.org/doi: 10.1207/S1 5324826AN0802_3] [PMID: $11515245]$

34. Rück C, Karlsson A, Steele JD, Edman G, Meyerson BA, Ericson K et al. Capsulotomy for obsessive-compulsive disorder. Arch. Gen. Psychiatry; 2008, 65(8): 914-922. [http://dx.doi.org/doi: 10.1001/archpsyc. 65.8.914] [PMID: 18678796].

35. Csigó K, Harsányi A, Demeter G, Rajkai C, Németh A, Racsmány M.. Long-term follow-up of patients with obsessive-compulsive disorder treated by anterior capsulotomy: A neuropsychological study. J Affect Disord 2010; 126 : 198-205. [http://dx.doi.org/doi:10.1016/j.jad.2010.02.127] [PMID: 20299108]

36. Mallet L, Mesnage V, Houeto JL, Pelissolo A, Yelnik J, Behar C et al. Compulsions, Parkinson's disease and stimulation. Lancet 2002 ;
360 : 1302-1304. [http://dx.doi.org/doi: 10.1016/S01406736(02) 11339-0] [PMID: 12414208].

37. Fontaine D, Mattei $V$, Borg $M$, von Langsdorff D, Magnie $M N$, Chanalet $S$ et al. Effect of subthalamic nucleus stimulation on obsessive-compulsive disorder in a patient with Parkinson disease. Case report. J Neurosurg; 2004, 100 : 1084-1086. [PMID: 15200126].

38. Mallet L, Polosan $M$, Jaafari N, Baup $N$, Welter ML, Fontaine D et al. Subthalamic nucleus stimulation in severe obsessive-compulsive disorder. N. Engl J Med; 2008, 359 : 2121-2134. [http://dx.doi.org/doi:10.1056/NEJMoa0708514] [PMID: 19005196].

39. MCKenna MT, Michaud CM, Murray CJ, Marks JS. Assessing the burden of disease in the United States using disability-adjusted life years. Am J Prev Med; 2005, 28 : 415-423.

[http://dx.doi.org/doi:10.1016/j.amepre.2005.02.009] [PMID 15894144].

40. Warden D, Rush AJ, Trivedi MH, Fava M, Wisniewski SR. The STAR*D Project results: a comprehensive review of findings. Curr. Psychiatry Rep 2007; 9 : 449-459. [http://dx.doi.org/doi:10.1007/s1 1920-0070061-3] [ PMID: 18221624]

41. Kopell BH, Greenberg B, Rezai AR. Deep brain stimulation for psychiatric disorders. J Clin Neurophysiol; 2004. 21 (1) : 51-67. [PMID: 15097294].

42. Cho DY, Lee WY, Chen CC. Limbic leukotomy for intractable major affective disorders: A 7-year follow-up study using nine comprehensive psychiatric test evaluations. J Clin Neurosci 2008; 15 : 138-142. [http://dx.doi.org/doi: 10.1016/j.jocn.2006.10.017] [PMID: 18068369].

43. Marangell LB, Rush AJ, George MS, Sackeim HA, Johnson CR, Husain $M M$ et al. Vagus nerve stimulation (VNS) for major depressive episodes: one year outcomes. Biol Psychiatry 2002; 51: 280-287. [http://dx.doi.org/doi:10.1016/S0006-3223(01)01343-9] [PMID: $11958778]$.

44. Sackeim HA, Rush AJ, George MS, Marangell LB, Husain MM, Nahas $Z$ et al. Vagus nerve stimulation (VNS) for treatment-resistant depression: efficacy, side effects, and predictors of outcome. Neuropsychopharmacology 2001; 25 : 713-728. [http://dx.doi.org/doi:10.1038/S0893-133X(01)00271-8] [PMID: $11682255]$.

45. Lakhan SE, Callaway E. Deep brain stimulation for obsessivecompulsive disorder and treatment-resistant depression: systematic review. BMC Res Notes 2010; 3:60. [http://dx.doi.org/doi:10.1186/1756-0500-3-60] [PMID: 20202203]

46. Lozano AM, Mayberg HS, Giacobbe P, Hamani C, Craddock RC, Kennedy SH. Subcallosal cingulate gyrus deep brain stimulation for treatment-resistant depression. Biol. Psychiatry 2008; 64 : 461-467. [http://dx.doi.org/doi:10.1016/j.biopsych.2008.05.034 [PMID:18639234].

47. Muzina DJ, Kemp DE, McIntyre RS. Differentiating bipolar disorders from major depressive disorders: treatment implications. Ann Clin Psychiatry 2007; 19 : 305-312. [http://dx.doi.org/10.1080/10401230701653591] [PMID: 18058287].

48. Machado-Vieira R, Manji HK, Zarate CA Jr. The role of lithium in the treatment of bipolar disorder: convergent evidence for neurotrophic effects as a unifying hypothesis. Bipolar Disord 2009; (Suppl. 2) : 92109. [http://dx.doi.org/doi:10.1111/j.1399-5618.2009.00714.x] [PMID: 19538689].

49. Nierenberg AA, Alpert JE, Gardner-Schuster EE, Seay S, Mischoulon D. Vagus nerve stimulation: 2-year outcomes for bipolar versus unipolar treatment-resistant depression. Biol Psychiatry 2008; 64 455-460. [http://dx.doi.org/doi:10.1016/j.biopsych.2008.04.036] [PMID: 18571625]. 